\title{
Cultivares de arroz de terras altas afetadas pelo manejo do solo
}

\author{
Adriano S. Nascente ${ }^{1}$, Priscila de Oliveira ${ }^{2}$, João Kluthcouski ${ }^{1}$, Roberto J. de Freitas ${ }^{3}$ \& José L. Favarin ${ }^{4}$ \\ 1 Embrapa Arroz e Feijão, Rodovia GO-462, km 12, Zona Rural CEP 75535-000, Goiania-GO, Brasil. Caixa Postal 179. E-mail: adriano.nascente@embrapa.br; \\ joao.kluthcouski@embrapa.br \\ ${ }^{2}$ Embrapa Cerrados, Rodovia BR 020, km 18, CEP 73310-970, Planaltina, DF, Brasil. Caixa Postal 08223. E-mail: priscila.oliveira@embrapa.br \\ ${ }^{3}$ Universidade Estadual de Goiás, Secretaria de Ciência e Tecnologia, Unidade Universitária de Ipameri, GO 330, km 241, Anel Viário, CEP 75780-000, Ipameri-GO, Brasil. \\ E-mail: rjf05@uol.com.br \\ ${ }^{4}$ Universidade de São Paulo, Escola Superior de Agricultura Luiz de Queiroz, Departamento de Produção Vegetal, Av. Pádua Dias, 11, Agronomia, CEP 13418-900, Piracicaba- \\ SP, Brasil. Caixa Postal 9. E-mail: favarin.esalq@usp.br
}

\section{RESUMO}

A identificação de cultivares melhores adaptadas a cada tipo de manejo do solo, poderá favorecer o aumento da produtividade da cultura do arroz de terras altas. $O$ objetivo do trabalho foi estudar o desempenho de genótipos de arroz de terras altas em dois sistemas de manejo do solo, preparo convencional com arado de aiveca (PC) e sistema plantio direto (SPD) nas condições do Cerrado. $O$ estudo foi conduzido em dois locais no município de Ipameri, GO, ano 2008/2009. O delineamento experimental foi em blocos ao acaso, no esquema fatorial $2 \times 5$, com cinco repetições. 0 primeiro fator foi o sistema de manejo do solo (PC e SPD) e 0 segundo era constituído das cultivares (BRS Sertaneja, BRS Primavera, BRS MG Curinga, Caiapó e BRS Bonança). As cultivares de arroz BRS Sertaneja, BRS MG Curinga, Caiapó e BRS Bonança tiveram maiores produtividades no PC que no SPD. A cultivar BRS Primavera teve produtividade semelhante nos dois sistemas de manejo do solo. A cultivar BRS Primavera foi a mais produtiva no SPD, e no PC as cultivares tiveram desenvolvimento semelhante. A produtividade de grãos do arroz foi maior na UEG-Ipameri que na Fazenda Santa Brígida.

Palavras-chave: arado de aiveca, Oryza sativa, produtividade, sistema plantio direto

\section{Cultivars of upland rice as affected by soil management}

\section{ABSTRACT}

The identification of cultivars more adapted for each type of soil management could increase the yield of upland rice. Therefore, this study aimed to evaluate rice genotypes in two systems of soil management, conventional tillage with moldbard plow (CT) and no-tillage system (NTS) under Cerrado conditions. The work was carried out in two places of the Ipameri municipality, in Goiás State, during 2008/2009 season. A randomized block design in a factorial scheme $2 \times 5$ with five replications was used. The first factor was composed of soil management (CT and NTS) and the second one was rice genotypes (BRS Sertaneja, BRS Primavera, BRS MG Curinga, Caiapó and BRS Bonança). The cultivars BRS Sertaneja, BRS MG Curinga, Caiapó e BRS Bonança had higher grain yield under CT compared to NTS. BRS Primavera had similar yield in both soil managements. The cultivar BRS Primavera was the most productive under NTS, and under CT cultivars had similar development. Upland rice grain yield was higher at UEG-Ipameri than at Santa Brígida Farm.

Key words: moldboard plow, Oryza sativa, productivity, no-tillage system 


\section{Introdução}

O cultivo do arroz de terras altas vem crescendo em importância mundial devido à redução da disponibilidade dos recursos hídricos, em virtude do aumento do consumo industrial e humano, principalmente na Ásia, onde se concentram 90\% da produção mundial (Farooq et al., 2009). Como alternativas tem-se o cultivo do arroz no ecossistema terras altas, no sistema irrigado por aspersão ou de sequeiro (Bouman et al., 2007; Cancellier et al., 2011; Fidelis et al., 2011; Arf et al., 2012).

Neste sentido, o sistema plantio direto (SPD), que devido à manutenção de palha, proporciona maior cobertura do solo, se caracteriza pelo maior armazenamento e conservação da umidade do solo (Nascente et al., 2012). Entretanto, a cultura do arroz de terras altas vem tendo, quando cultivado em SPD, baixa produtividade não se desenvolvendo da mesma forma que quando o cultivo ocorre em solo preparado convencionalmente (PC), ou seja, com revolvimento (Kluthcouski et al., 2000; Nascente et al., 2013). Com isto, a maioria das áreas cultivadas com essa cultura ainda é feita sob PC, isto é normalmente uma aração e duas gradagens (Santos et al., 2006). Ressalta-se, entretanto, que a utilização desse sistema pode causar erosão do solo; assoreamento dos rios; formação de camada compactada, conhecida como pé de grade ou pé de arado; diminuição da atividade biológica do solo; aumento da temperatura do solo e menor conservação da umidade, dentre outros (Kluthcouski et al., 2000).

No entanto, devido ao trânsito de máquinas e implementos agrícolas pode ocorrer, no SPD, redução da macroporosidade e, como a planta de arroz possui sistema radicular muito sensível à compactação do solo, as raízes ficam menos profundas (Guimarães et al., 2006). Assim, a planta com o sistema radicular menos desenvolvido explora menos o perfil do solo, ficando mais sujeita aos efeitos do veranico e absorve menos nutrientes, o que tem acarretado queda de produtividade (Kluthcouski et al., 2000; Guimarães et al., 2006; Nunes et al., 2012); desta forma, diversos autores atribuíram a menor produtividade de grãos do arroz ao maior adensamento do solo observado neste sistema (Stone et al., 2001; Kluthcouski et al., 2000; Guimarães \& Moreira, 2001; Moura Neto et al., 2002; Guimarães et al., 2006). Neste contexto verifica-se que uma das alternativas seria o rompimento da camada compactada/ adensada. Isso pode ser realizado com máquinas por meio da descompactação mecânica (PC) ou pelas plantas de cobertura (SPD) que possuem potencial para descompactar camadas adensadas, podendo contribuir para o melhor desenvolvimento do arroz em SPD (Bordin et al., 2008; Calonego \& Rosolem, 2010; Nascente, 2012; Nascente et al., 2013).

Assim, Guimarães et al. (2006) relataram diferenças na produtividade de grãos de cultivares de arroz em diferentes ambientes, com algumas mais produtivas no SPD e outras no PC. Nascente et al. (2011a) observaram, avaliando oito cultivares de arroz de terras altas que, apesar da maior produtividade média obtida no sistema convencional (4.349 $\left.\mathrm{kg} \mathrm{ha}^{-1}\right)$ em relação ao SPD (3.521 $\left.\mathrm{kg} \mathrm{ha}^{-1}\right)$, a cultivar BRS MG Curinga teve produtividade semelhante nos dois sistemas. Adicionalmente, Moura Neto et al. (2002) constataram que as produtividades médias de 14 materiais foram de $5.606 \mathrm{e}$ $5.608 \mathrm{~kg} \mathrm{ha}^{-1}$ para o SPD e PC respectivamente, sendo que também foi verificada interação entre cultivares e sistema de preparo do solo reforçando a necessidade de se identificar os materiais mais adaptados a cada sistema; desta forma pode-se inferir, com esses trabalhos, que a escolha da cultivar é fator determinante, a ponto de comprometer a viabilidade dessa cultura no SPD. Entretanto, apesar de poucos, ainda existem estudos sobre o comportamento de cultivares em ambiente SPD; neste sentido o trabalho teve como objetivo avaliar o desempenho de genótipos de arroz de terras altas sob Cerrado no sistema de manejo do solo com preparo convencional e no sistema plantio direto.

\section{Material e Métodos}

$\mathrm{O}$ experimento em condições de sequeiro foi conduzido no ano agrícola de 2008/2009, em dois locais, no município de Ipameri-GO. Local 1 - Fazenda Santa Brígida, a $17^{\circ} 39^{\prime}$ $27^{\prime \prime}$ de latitude Sul, $48^{\circ} 12^{\prime} 22^{\prime \prime}$ de longitude Oeste e $800 \mathrm{~m}$ de altitude. O solo da área experimental é classificado como Latassolo Vermelho distrófico, manejado sob SPD há quatro anos (2004/2005, 2005/2006 e 2006/2007 - soja no verão/ pousio no inverno; 2007/2008 - milho + Brachiaria brizantha no verão e pasto no inverno). Local 2 - Fazenda experimental da Universidade Estadual de Goiás - Unidade Universitária de Ipameri (UEG-Ipameri), a $17^{\circ} 13^{\prime} 00^{\prime \prime}$ de latitude Sul e $48^{\circ} 22^{\prime} 00^{\prime \prime}$ de longitude Oeste e $760 \mathrm{~m}$ de altitude. O solo é caracterizado como Latossolo Vermelho-Amarelo, sendo utilizado como pastagem de Brachiaria decumbens nos vinte anos antecessores.

O clima do município é classificado como tropical de altitude, Cwa na classificação de Köppen. A temperatura média é de $25{ }^{\circ} \mathrm{C}$ com precipitação pluviométrica média anual de $1.750 \mathrm{~mm}$; adicionalmente, apresenta-se o balanço hídrico mensal do município de Ipameri-GO como forma de caracterização climática da região (Figura 1). Antes da instalação dos experimentos foram coletadas amostras nos dois locais para análise química do solo nas camadas 0 a $20 \mathrm{~cm}$ e 20 a $40 \mathrm{~cm}$ (Tabela 1).

O delineamento experimental foi em blocos ao acaso, em esquema fatorial $2 \times 5$, com cinco repetições. Os tratamentos



Jan Fev Mar Abr Mai Jun Jul Ago Set Out Nov Dez

Figura 1. Balanço hídrico mensal do município de Ipameri-GO (Sentelhas et al., 2010). DEF: déficit de água no solo. EXC: excedente de água no solo 
Tabela 1. Atributos químicos do solo na profundidade de 0 a 20 e 20 a $40 \mathrm{~cm}$ antes da instalação dos experimentos, no verão de $2008 / 2009$ em dois locais do município de Ipameri-GO

\begin{tabular}{|c|c|c|c|c|c|c|c|c|c|c|c|c|}
\hline \multirow{2}{*}{$\begin{array}{l}\text { Prof. } \\
(\mathrm{cm})\end{array}$} & \multirow{2}{*}{$\begin{array}{c}\text { pH } \\
\text { (água) }\end{array}$} & $\mathbf{C a}$ & Mg & Al & $\mathbf{H}+\mathbf{A l}$ & $\mathbf{P}$ & $\mathbf{K}$ & $\mathrm{Cu}$ & Zn & Fe & Mn & \multirow{2}{*}{$\begin{array}{c}\mathrm{MO} \\
\mathrm{g} \mathrm{dm}^{-3}\end{array}$} \\
\hline & & \multicolumn{4}{|c|}{$\mathrm{cmol}_{\mathrm{c}} \mathrm{dm}^{-3}$} & \multicolumn{6}{|c|}{$\mathrm{mg} \mathrm{dm}^{-3}$} & \\
\hline \multicolumn{13}{|c|}{ Local 1 - Fazenda Santa Brígida } \\
\hline $0-20$ & 6,3 & 2,0 & 0,9 & 0,0 & 3,6 & 7,9 & 145 & 2,7 & 6,2 & 37 & 31 & 20 \\
\hline $20-40$ & 5,7 & 0,8 & 0,4 & 0,1 & 3,5 & 0,8 & 39 & 2,5 & 0,9 & 38 & 14 & 12 \\
\hline \multicolumn{13}{|c|}{ Local 2 - UEG Ipameri } \\
\hline $0-20$ & 5,4 & 0,27 & 0,14 & 0,4 & 4,9 & 0,6 & 44 & 1,3 & 0,6 & 99 & 19 & 16 \\
\hline $20-40$ & 5,4 & 0,18 & 0,11 & 0,3 & 5,1 & 0,2 & 30 & 1,6 & 0,6 & 72 & 13 & 12 \\
\hline
\end{tabular}

se constituíram da combinação de dois manejos do solo (PC e SPD) com cinco cultivares de arroz de terras altas (BRS Sertaneja, BRS Primavera, BRS MG Curinga, Carajás e BRS Bonança), conduzidos em dois locais do município de Ipameri, GO. As parcelas experimentais foram constituídas de oito linhas de arroz com cinco metros de comprimento, sendo a parcela útil composta pelas duas linhas centrais, desprezandose $0,5 \mathrm{~m}$ de cada lado, conforme utilizado por Nascente et al. (2013), Nascente et al. (2012), Nascente (2012), Nunes et al. (2012), Moro (2011), Nascente et al. (2011a), Nascente et al. (2011b), Pacheco et al. (2011), Guimarães et al. (2006), Guimaraes \& Moreira (2001) e Kluthcouski et al. (2000).

O preparo convencional do solo foi realizado com arado de aiveca, 15 dias antes da semeadura, seguido de uma gradagem niveladora, no dia da semeadura. No SPD a dessecação da cultura antecessora (Brachiaria brizantha no local 1 e $B$. decumbens no local 2) foi realizada 20 dias antes da semeadura, com o herbicida glyphosate na dose de $1,8 \mathrm{~kg}$ $\mathrm{ha}^{-1}$ de equivalente ácido (e.a.).

A semeadura foi realizada no dia 25/11/2008 (local 1) e 27/11/2008 (local 2) com densidade de 100 sementes $\mathrm{m}^{-1}$, utilizando-se semeadora-adubadora com espaçamento entre linhas de $0,45 \mathrm{~m}$. A adubação básica do sulco de semeadura foi constituída de $400 \mathrm{~kg} \mathrm{ha}^{-1}$ da fórmula 08-20-15 ( $\mathrm{N}_{2} \mathrm{P}_{2} \mathrm{O}_{5}$ $\mathrm{K}_{2} \mathrm{O}$ ). As sementes foram tratadas com inseticida à base de carbofuran, 310 g i.a. L-1 (Furazin $310 \mathrm{FS}$ ) na dose de $2 \mathrm{~L}$ do produto comercial para $100 \mathrm{~kg}$ de sementes. Fez-se a adubação de cobertura aos 15 dias após a emergência da cultura aplicando-se $67,5 \mathrm{~kg} \mathrm{ha}^{-1}$ de nitrogênio $(\mathrm{N})$ na forma de ureia. Os tratos culturais nas cultivares foram realizados de acordo com a necessidade da cultura (Santos et al., 2006).

As operações de ceifa, trilha e limpeza dos grãos, foram realizadas manualmente e avaliadas as seguintes características: altura de plantas (com o uso de régua, foram medidas 10 plantas ao acaso, em cada parcela), perfilhamento (contou-se o número de perfilhos de 10 plantas escolhidas ao acaso nas duas linhas centrais das parcelas) e produtividade em que após a maturação fisiológica da cultura, foram colhidas todas as panículas da área útil e os grãos foram pesados. A umidade foi ajustada para $130 \mathrm{~g} \mathrm{~kg}^{-1} \mathrm{e}$ os dados transformados para $\mathrm{kg} \mathrm{ha}^{-1}$. Todos os efeitos dos tratamentos foram avaliados por meio da análise de variância e teste comparativo de médias de Tukey a $5 \%$ de probabilidade através do programa estatístico SAS.

\section{Resultados e Discussão}

\section{Altura de plantas}

Analisando a variável altura, verificou-se que no fator cultivares a cultivar Caiapó teve a maior altura $(116,5 \mathrm{~cm})$ diferindo das demais (Tabela 2). Com relação aos locais e manejo do solo, as cultivares tiveram altura de plantas semelhantes.

Tabela 2. Altura de plantas, número de perfilhos e produtividade de grãos de arroz de terras altas em razão das cultivares, manejo do solo e local do experimento. Ipameri, GO

\begin{tabular}{|c|c|c|c|}
\hline Fatores & $\begin{array}{c}\text { Altura } \\
\text { cm }\end{array}$ & $\begin{array}{c}\text { Perfilhos } \\
\text { Número } \mathbf{m}^{-1} \\
\end{array}$ & $\begin{array}{c}\text { Produtividade } \\
\mathrm{kg} \mathrm{ha}^{-1}\end{array}$ \\
\hline \multicolumn{4}{|l|}{ Cultivares } \\
\hline BRS Sertaneja & $108,1 b^{1}$ & $168 \mathrm{c}$ & $3.423 a$ \\
\hline BRS Primavera & $107,6 \mathrm{~b}$ & $165 \mathrm{c}$ & $3.601 \mathrm{a}$ \\
\hline BRS MG Curinga & $96,5 \mathrm{c}$ & $230 \mathrm{a}$ & $3.548 \mathrm{a}$ \\
\hline Caiapó & $116,5 \mathrm{a}$ & $178 \mathrm{bc}$ & $3.332 \mathrm{a}$ \\
\hline BRS Bonança & $88,9 \mathrm{c}$ & $192 b$ & $3.240 \mathrm{a}$ \\
\hline \multicolumn{4}{|l|}{ Manejo solo } \\
\hline SPD & $100,1 \mathrm{a}$ & $190 \mathrm{a}$ & $3.162 b$ \\
\hline Aiveca & $106,8 \mathrm{a}$ & $184 \mathrm{a}$ & $3.696 \mathrm{a}$ \\
\hline \multicolumn{4}{|l|}{ Local do experimento } \\
\hline Fazenda Santa Brígida & $104,8 \mathrm{a}$ & $263 a$ & $3.080 \mathrm{~b}$ \\
\hline UEG-Ipameri & $102,2 \mathrm{a}$ & $111 \mathrm{~b}$ & $3.778 \mathrm{a}$ \\
\hline Fatores & \multicolumn{3}{|c|}{ ANAVA (Probabilidade do teste F) } \\
\hline Cultivares (C) & $<0,001$ & $<0,001$ & 0,2321 \\
\hline Manejo solo (M) & 0,1714 & 0,2903 & $<0,001$ \\
\hline Local do experimento (L) & 0,4768 & $<0,001$ & $<0,001$ \\
\hline $\mathrm{C} \times \mathrm{M}$ & 0,0439 & 0,0375 & 0,0497 \\
\hline$C \times L$ & 0,0231 & 0,1803 & 0,0456 \\
\hline$M \times L$ & 0,6784 & 0,7388 & 0,6319 \\
\hline$C \times M \times L$ & 0,6942 & 0,7112 & 0,7004 \\
\hline
\end{tabular}

Médias seguidas de mesma letra, na coluna, não diferem entre si pelo teste Tukey, $p<0,05$

Houve interação entre o local do experimento e cultivares para essa variável (Tabela 3). Assim, na Fazenda Santa Brígida a cultivar Caiapó foi a mais alta $(121,6 \mathrm{~cm})$, e diferente das demais cultivares. Na UEG-Ipameri, as cultivares BRS MG Curinga $(90,6 \mathrm{~cm})$ e BRS Bonança $(88,8 \mathrm{~cm})$ foram as mais baixas e diferiram das demais cultivares. BRS Sertaneja (107,5 e 108,7 cm na Fazenda Santa Brígida e UEG-Ipameri, respectivamente) e BRS Bonança (88,9 e $88,8 \mathrm{~cm}$ na Fazenda Santa Brígida e UEG-Ipameri, respectivamente) tiveram alturas semelhantes nos dois locais. BRS Primavera foi mais baixa na Fazenda Santa Brígida $(103,8 \mathrm{~cm})$ do que na UEG-Ipameri $(111,4 \mathrm{~cm})$; já as cultivares BRS MG Curinga (102,3 e 90,6 cm na Fazenda Santa Brígida e UEG-Ipameri, respectivamente) e Caiapó (121,6 e 111,3 cm na Fazenda Santa Brígida e UEG-Ipameri, respectivamente) tiveram maior altura no primeiro local.

Ocorreu interação entre as cultivares e os manejos do solo (Tabela 4). Verifica-se, então, que no SPD as cultivares BRS Sertaneja $(108,2 \mathrm{~cm})$, BRS Primavera $(104,0 \mathrm{~cm})$ e Caiapó $(111,0 \mathrm{~cm})$ foram as mais altas e diferentes das demais, enquanto no PC Caiapó $(121,9 \mathrm{~cm})$ foi a cultivar estatisticamente mais alta. Na comparação dos manejos do solo observa-se que se teve, no PC, as maiores alturas para as 
Tabela 3. Efeito da interação entre local do experimento e cultivares para altura de plantas e produtividade de grãos de arroz de terras altas. Ipameri, GO

\begin{tabular}{|c|c|c|}
\hline \multirow{2}{*}{ Cultivares } & \multicolumn{2}{|c|}{ Local do experimento } \\
\hline & Fazenda Santa Brígida & UEG-Ipameri \\
\hline & \multicolumn{2}{|c|}{ Altura $(\mathrm{cm})$} \\
\hline BRS Sertaneja & $107,5 \mathrm{bA} !$ & 108,7 a A \\
\hline BRS Primavera & 103,8 b B & 111,4 a $A$ \\
\hline BRS MG Curinga & $102,3 \mathrm{bA}$ & 90,6 b B \\
\hline Caiapó & 121,6 a A & 111,3 a B \\
\hline \multirow[t]{2}{*}{ BRS Bonança } & $88,9 \mathrm{cA}$ & 88,8 b A \\
\hline & \multicolumn{2}{|c|}{ Produtividade $\left(\mathrm{kg} \mathrm{ha}^{-1}\right)$} \\
\hline BRS Sertaneja & 3.054 a B & $3.792 \mathrm{ab} \mathrm{A}$ \\
\hline BRS Primavera & 3.182 a B & 4.021 a A \\
\hline BRS MG Curinga & 3.145 a B & $3.951 \mathrm{ab} A$ \\
\hline Caiapó & 3.123 a $A$ & $3.541 \mathrm{~b} \mathrm{~A}$ \\
\hline BRS Bonança & 2.896 a B & $3.584 \mathrm{bA}$ \\
\hline
\end{tabular}

Tabela 4. Efeito da interação entre manejo do solo e cultivares para altura de plantas, número de perfilhos e produtividade de grãos do arroz de terras altas. Ipameri, GO

\begin{tabular}{|c|c|c|}
\hline \multirow{2}{*}{ Cultivares } & \multicolumn{2}{|c|}{ Manejo do solo } \\
\hline & SPD & Aiveca \\
\hline & \multicolumn{2}{|c|}{ Altura $(\mathrm{cm})$} \\
\hline BRS Sertaneja & $108,2 a^{1}$ & $108,0 \mathrm{bA}$ \\
\hline BRS Primavera & 104,0 a B & $111,2 \mathrm{~b} \mathrm{~A}$ \\
\hline BRS MG Curinga & $95,0 \mathrm{bA}$ & $97,9 \mathrm{cA}$ \\
\hline Caiapó & 111,0 a B & 121,9 a A \\
\hline \multirow[t]{2}{*}{ BRS Bonança } & 82,5 c B & $95,2 \mathrm{cA}$ \\
\hline & \multicolumn{2}{|c|}{ Perfilhos (número $\mathrm{m}^{-1}$ ) } \\
\hline BRS Sertaneja & $173 \mathrm{~cd} A$ & $164 \mathrm{bA}$ \\
\hline BRS Primavera & $160 \mathrm{dA}$ & $170 \mathrm{bA}$ \\
\hline BRS MG Curinga & 244 a A & 215 a B \\
\hline Caiapó & $194 \mathrm{bA}$ & 162 b B \\
\hline \multirow[t]{2}{*}{ BRS Bonança } & $177 \mathrm{c} \mathrm{B}$ & 207 a $A$ \\
\hline & \multicolumn{2}{|c|}{ Produtividade $\left(\mathrm{kg} \mathrm{ha}^{-1}\right)$} \\
\hline BRS Sertaneja & 3.022 b B & 3.825 a $A$ \\
\hline BRS Primavera & 3.559 a A & 3.644 a A \\
\hline BRS MG Curinga & $3.199 a b B$ & 3.897 a A \\
\hline Caiapó & 3.065 b B & $3.600 \mathrm{aA}$ \\
\hline BRS Bonança & $2.966 \mathrm{~b} \mathrm{~B}$ & 3.514 a A \\
\hline
\end{tabular}

cultivares BRS Primavera (104,0 e 111,2 $\mathrm{cm}$ para SPD e PC, respectivamente), Caiapó (111,0 e 121,9 cm para SPD e PC, respectivamente) e BRS Bonança (82,5 e 95,2 cm para aiveca e SPD, respectivamente).

Das cinco cultivares utilizadas observa-se, para três (BRS Primavera, Caiapó e BRS Bonança) que o PC proporcionou maior crescimento das plantas do que no sistema plantio direto (SPD) (Tabela 4). Devido ao revolvimento do solo, geralmente se observa, no PC, melhora nas condições do solo para o crescimento das plantas, especialmente quando existem camadas compactadas (Kluthcouski et al., 2000). Possivelmente esse tipo de preparo proporcionou condições para o melhor desenvolvimento do sistema radicular aproveitando mais água e nutrientes resultando, portanto, em plantas mais desenvolvidas. Segundo Arf et al. (2001) em solos não compactados as plantas têm melhor desenvolvimento. A média de altura para as cultivares no PC foi de $107 \mathrm{~cm}$, valores próximos aos obtidos por Arf et al. (2001) e Nascente et al. (2011a) característica esta importante, pois cultivares de porte alto e colmo fraco podem acamar mais facilmente, em especial quando recebem altas doses de nitrogênio, uma vez que este nutriente estimula o desenvolvimento foliar e o crescimento das plantas. O acamamento diminui a seção transversal dos feixes vasculares e, em contrapartida, reduz o movimento dos fotoassimilados e dos nutrientes absorvidos pelas raízes e, em consequência, a produtividade do arroz diminui (Guimarães et al., 2006). Além disto, aumenta o autossombreamento, contribuindo para maior esterilidade de grãos. Por outro lado, colmos mais curtos facilitam a respiração e aumentam o aproveitamento dos produtos fotossintéticos. Entretanto, o porte extremamente baixo não é vantajoso porque também induz ao aumento do autossombreamento. Portanto, a planta deve ter porte intermediário para resistir ao acamamento e ter menor autossombreamento (Santos et al., 2006).

\section{Número de perfilhos $\mathbf{m}^{-1}$}

A cultivar BRS MG Curinga se destacou (230) diferindo das outras cultivares (Tabela 2); no manejo do solo, verificase que houve valores semelhantes; com relação aos locais, o número de perfilhos foi maior na Fazenda Santa Brígida (263) do que na UEG-Ipameri (111).

Constata-se, então, que a cultivar BRS MG Curinga no SPD se destacou (244) e diferiu das demais cultivares; no preparo com aiveca BRS MG Curinga (215) e BRS Bonança (207) foram diferentes das outras cultivares (Tabela 3). Comparando os dois sistemas de manejo do solo observa-se que as cultivares BRS Sertaneja (173 e 164 perfilhos $\mathrm{m}^{-1}$ no SPD e PC, respectivamente) e BRS Primavera (160 e 170 perfilhos $\mathrm{m}^{-1}$ no SPD e PC, respectivamente) tiveram resultados semelhantes no SPD e aiveca. As cultivares BRS MG Curinga (244 e 215 perfilhos $\mathrm{m}^{-1}$ no SPD e PC, respectivamente) e Caiapó (194 e 162 perfilhos $\mathrm{m}^{-1}$ no SPD e PC, respectivamente) tiveram maior valor no SPD. A cultivar BRS Bonança, teve maior número de perfilhos no PC (207) do que no SPD (177).

A cultivar BRS MG Curinga se destacou em ambos os sistemas de manejo do solo (Tabela 3). Resultados semelhantes foram obtidos por Nascente et al. (2011a) ao relatarem que essa cultivar tem característica de possuir alto perfilhamento. Vale destacar a estabilidade para perfilhamento dos materiais BRS Sertaneja e BRS Primavera, que tiveram valores semelhantes nos dois manejos. Segundo Santos et al. (2006) genótipos perfilhadores têm vantagens por se adaptar a vários espaçamentos e densidades de semeadura e, ainda, compensar a semeadura irregular. Entretanto Guimarães et al. (2006) ressaltam que perfilhamento intenso pode ser prejudicial à cultura, caso ocorra déficit hídrico, e os autores recomendam, para as condições de distribuição hídrica irregular, comum na região dos Cerrados, que a estabilidade produtiva das cultivares demanda perfilhamento baixo a moderado, raízes profundas e finas, entre outras características para conferir a essas cultivares, maior adaptação à seca. Santos et al. (2006) também advertem que alto perfilhamento pode ser prejudicial em razão do maior autossombreamento; corroborando com esta informação, observou-se maior número de perfilhos no experimento da Fazenda Santa Brígida, o que não se traduziu em maior produtividade (Tabela 3 ).

\section{Produtividade de grãos}

As cultivares tiveram comportamento semelhante não se encontrando diferenças entre si (Tabela 2). No manejo do solo 
a produtividade no PC (3.696 $\left.\mathrm{kg} \mathrm{ha}^{-1}\right)$ foi maior do que no SPD (3.162 $\mathrm{kg} \mathrm{ha}^{-1}$ ) (Tabela 3). Observa-se que BRS Primavera $\left(3.559 \mathrm{~kg} \mathrm{ha}^{-1}\right)$ foi a mais produtiva no $\mathrm{SPD}$, não diferindo da cultivar BRS MG Curinga (3.199 $\mathrm{kg} \mathrm{ha}^{-1}$ ) mas diferindo das outras cultivares. No PC, as cultivares tiveram produtividades semelhantes. Na comparação dos sistemas de manejo do solo, com exceção da BRS Primavera (3.559 e $3.644 \mathrm{~kg} \mathrm{ha}^{-1}$ no SPD e PC, respectivamente), todas as cultivares tiveram maior produtividade quando o solo foi submetido ao PC.

As cultivares tiveram valores semelhantes na Fazenda Santa Brígida e não diferiram entre si (Tabela 2). Entretanto, houve interação entre o local do experimento e cultivares para produtividade de grãos (Tabela 3). Na UEG-Ipameri, BRS Primavera foi a mais produtiva $\left(4.021 \mathrm{~kg} \mathrm{ha}^{-1}\right)$, não diferindo da BRS MG Curinga (3.951 kg ha'-1) e BRS Sertaneja (3.792 $\mathrm{kg} \mathrm{ha}^{-1}$ ) porém diferindo da Caiapó (3.541 $\mathrm{kg} \mathrm{ha}^{-1}$ ) e BRS Bonança $\left(3.584 \mathrm{~kg} \mathrm{ha}^{-1}\right)$. Com relação aos locais, somente Caiapó ( 3.123 e $3.541 \mathrm{~kg} \mathrm{ha}^{-1}$ ) teve valores semelhantes em ambas as localidades; as demais tiveram maiores valores na UEG-Ipameri.

A produtividade média (3.696 $\mathrm{kg} \mathrm{ha}^{-1}$ ) no PC (Tabela 2), foi superior à obtida por Arf et al. 2001, que obtiveram média de $3.419 \mathrm{~kg} \mathrm{ha}^{-1} \mathrm{e}$ inferior à obtida por Nascente et al. (2011a), que relataram produtividade de $4.349 \mathrm{~kg} \mathrm{ha}^{-1}$. Segundo Guimarães et al. (2006) as cultivares respondem diferentemente ao ambiente com relação à produtividade de grãos. Com o SPD obteve-se produtividade de $3.162 \mathrm{~kg} \mathrm{ha}^{-1}$, média superior à da Região Centro Oeste, que foi de $2.932 \mathrm{~kg} \mathrm{ha}^{-1}$ na safra 2008/2009 (Conab, 2009). Assim, a produtividade no SPD, apesar de ter sido inferior ao PC, foi quase $10 \%$ superior à média da Região sinal de que o uso do SPD pode ser uma alternativa viável para as condições de Cerrado.

A produtividade de grãos do arroz foi superior na UEGIpameri em relação à Fazenda Santa Brígida, para todas as cultivares, com exceção da Caiapó. Esta maior produtividade pode ser explicada em virtude de que, na UEG-Ipameri, a área se encontrava em pastagem há 20 anos e neste ambiente a forma de nitrogênio mineral amoniacal está mais disponível devido, sobremaneira, aos menores valores de $\mathrm{pH}$ (5,4, Tabela 1), que, em geral, ocorrem, nessas condições (Moreira \& Siqueira, 2002; Lin et al., 2005; Li et al., 2007; Crusciol et al., 2011; Poletto et al., 2011; Araújo et al., 2012). Por outro lado foram verificados, na Fazenda Santa Brígida; maiores valores de $\mathrm{pH}(6,3)$, que podem ter contribuído para maior nitrificação, o que poderia ser mais prejudicial ao desenvolvimento da cultura. Segundo Malavolta (1980), Kronzucker et al. (1998); Lin et al. (2005); Li et al. (2007); Holzschuh et al. (2009), Moro (2011), Poletto et al. (2011), Nascente (2012) e Araújo et al. (2012) o arroz, por sua origem hidrófila, se desenvolve melhor em ambientes com maiores teores de amônio no início de seu desenvolvimento. Neste sentido e apesar de não terem sido avaliados os teores de amônio e nitrato no solo pelos valores de $\mathrm{pH}$ obtidos em cada área, pode-se inferir que esta origem tenha sido causa da maior produtividade obtida no local 2. De acordo Crusciol et al (2011) os maiores valores de $\mathrm{pH}$ próximos à neutralidade, como observado no local 1 $(6,3$, tabela 1$)$ podem promover aumento na disponibilidade de nitrato. Adicionalmente, Santos et al. (2006) relatam que o aumento do $\mathrm{pH}$ acima de 5,3 pode causar diminuição na produção do arroz.

Comparando a produtividade das cultivares nos dois sistemas verificou-se que o PC possibilitou maior produtividade a todas as cultivares, com exceção da cultivar BRS Primavera. Este resultado é semelhante ao obtido por Kluthcouski et al. (2000) e Nascente et al. (2011a) que avaliaram o desenvolvimento de cultivares de arroz em diversos sistemas de manejo do solo e observaram que em SPD os materiais tiveram menor média de produtividade de grãos, com redução de $31 \%$ e $19 \%$, respectivamente, em relação ao PC. No presente trabalho esta redução foi de $14 \%$. Uma das razões atribuídas para esta queda da produtividade da cultura é a presença de compactação superficial, com redução da macroporosidade do solo, que prejudica o crescimento e o estabelecimento das plântulas. Esta mesma observação já foi descrita por outros autores (Kluthcouski et al., 2000; Arf et al., 2001; Moura Neto et al., 2002; Nascente et al., 2011a, 2011b; Pacheco et al., 2011), que apontam o arroz como cultura que tem dificuldade no estabelecimento de plantas sobretudo quando há camada superficial compactada, ocorrência comum no SPD (Kluthcouski et al., 2000; Guimarães \& Moreira, 2001). Neste contexto, verifica-se que uma das alternativas seria o rompimento da camada compactada utilizando-se plantas de cobertura com sistema radicular vigoroso, como descrito por outros autores (Bordin et al., 2008; Calonego \& Rosolem, 2010). Entretanto, apesar da baixa produtividade do arroz obtida no SPD (Tabela 3) em relação ao PC, alguns autores relataram viabilidade no uso desta cultura, no ambiente (Moura Neto et al., 2002; Guimarães et al., 2006; Moro, 2011; Nascente et al., 2011a, 2011b; Pacheco et al., 2011; Nascente et al., 2012; Nascente et al., 2013). Com essas controvérsias constata-se que existem vários fatores que têm interferido no desenvolvimento do arroz de terras altas em SPD e necessitam ser melhor compreendidos; dentre esses fatores pode-se inferir que a escolha da cultivar é fator determinante, a ponto de comprometer a viabilidade dessa cultura no SPD (Moura Neto et al., 2002; Guimarães et al., 2006; Nascente et al., 2011a). Com os resultados obtidos verifica-se melhor adaptação da cultivar BRS Primavera para o SPD. Segundo Cancellier et al. (2011), a cultivar BRS Primavera é uma das mais responsivas à aplicação do nitrogênio com a maior produtividade de grãos em relação às outras cinco cultivares avaliadas.

Neste sentido, Moura Neto et al. (2002) relataram que, na ocasião da semeadura, principalmente com nitrogênio, a adubação aumentou substancialmente a produtividade de grãos no arroz em SPD. Nascente et al. (2011b) observaram produtividades similares do arroz de terras altas no SPD e no PC quando, além da adubação de semeadura $\left(20 \mathrm{~kg} \mathrm{ha}^{-1} \mathrm{de} \mathrm{N}\right)$, foram aplicados $45 \mathrm{~kg} \mathrm{ha}^{-1}$ de $\mathrm{N}$, um dia antes do semeio da cultura. Adicionalmente, vale destacar que a escolha da espécie de planta de cobertura para o arroz também é característica importante para viabilizar o arroz no SPD enquanto o uso de espécies de Brachiaria parece não ser a mais recomendado, haja vista que a produtividade obtida no SPD foi inferior ao PC (Tabela 4). Souza Filho et al. (1997), Souza et al. (2006) e Martins et al. (2006) relataram efeitos alelopáticos causados 
por espécies de Brachiaria, segundo os quais referidos efeitos podem reduzir a germinação de sementes das culturas e o desenvolvimento da planta, com reflexo na produtividade de grãos. Por outro lado, tem-se verificado produtividade de grãos de arroz igual ou superior ao PC quando se utilizou o milheto como cultura de cobertura (Arf et al., 2003; Moro, 2011; Pacheco et al., 2011). Verifica-se, então, a necessidade de se estudar quais as plantas de cobertura devem anteceder o arroz para evitar prováveis efeitos alelopáticos.

\section{Conclusões}

As cultivares de arroz BRS Sertaneja, BRS MG Curinga, Caiapó e BRS Bonança tiveram maiores produtividades no PC que no SPD;

A cultivar BRS Primavera teve produtividade semelhante nos dois sistemas de manejo do solo;

A cultivar BRS Primavera foi a mais produtiva no SPD e no $\mathrm{PC}$ as cultivares apresentaram desenvolvimento semelhante;

A produtividade de grãos do arroz foi maior na UEGIpameri do que na Fazenda Santa Brígida.

\section{Agradecimentos}

Os autores agradecem aos funcionários da Fazenda Santa Brígida, da Universidade Estadual de Goiás, Unidade Universitária Ipameri, pelo apoio local, e à Embrapa pelo apoio técnico.

\section{Literatura Cltada}

Araújo, J. L.; Faquin, V.; Vieira, N. M. B.; Oliveira, M. V. C.; Soares, A. A.; Rodrigues, C. R.; Mesquita,A. C. Crescimento e produção do arroz sob diferentes proporções de Nitrato e de Amônio. Revista Brasileira de Ciência do Solo, v.36, n.3, p.921-930, 2012. <http://dx.doi.org/10.1590/S0100$06832012000300022>$.

Arf, O.; Nascimento, V. do; Rodrigues, R. A. F.; Alvarez, R. de C. F.; Gitti, D. de C.; Sá, M. E. de. Uso de etiltrinexapac em cultivares de arroz de terras altas. Pesquisa Agropecuária Tropical, v.42, n.2, p.150-158, 2012. <http:// dx.doi.org/10.1590/S1983-40632012000200008>.

Arf, O.; Rodrigues, R. A. F.; Crusciol, C. A. C.; Sá, M. E. de; Buzetti, S. Soil management and nitrogen fertilization for sprinkler-irrigated upland rice cultivars. Scientia Agricola, v.60, n.2, p.345-352, 2003. <http://dx.doi.org/10.1590/ S0103-90162003000200020>.

Arf, O.; Rodrigues, R. A. F.; Sá, M. E. de; Crusciol, C. A. C. Resposta de cultivares de arroz de sequeiro ao preparo do solo e à irrigação por aspersão. Pesquisa Agropecuária Brasileira, v.36, n.6, p.871-879, 2001. <http://dx.doi. org/10.1590/S0100-204X2001000600004>.

Bordin, I.; Neves, C. S. V. J.; Medina, C. C.; Santos, J. C. F. dos; Torres, E.; Urquiaga, S. Matéria seca, carbono e nitrogênio de raízes de soja e milho em plantio direto e convencional. Pesquisa Agropecuária Brasileira, v.43, n.12, p.1785-1792, 2008. <http://dx.doi.org/10.1590/ S0100-204X2008001200020>.
Bouman, B. A. M.; Feng, L.; Tuong, T. P.; Lu, G.; Wang, H.; Feng, Y. Exploring options to grow rice using less water in northern China using a modeling approach. II: Quantifying yield, water balance components, and water productivity. Agricultural Water Management, v.88, n.1/3, p.23-33, 2007. <http://dx.doi.org/10.1016/j.agwat.2006.10.005>.

Calonego, J. C.; Rosolem, C. A. Soybean root growth and yield in rotation with cover crops under chiseling and notill. European Journal of Agronomy, v.33, n.3, p.242-249, 2010. <http://dx.doi.org/10.1016/j.eja.2010.06.002>.

Cancellier, E.; Barros, H. B.; Kischel, E.; Gonzaga, L. A. de M.; Brandão, D. R.; Fidelis, R. R. Eficiência agronômica no uso de nitrogênio mineral por cultivares de arroz de terras altas. Revista Brasileira de Ciências Agrárias, v.6, n.4, p.650-656, 2011. <http://dx.doi.org/10.5039/agraria.v6i4a1420>.

Companhia Brasileira de Abastecimento - Conab. Acompanhamento de safra brasileira: grãos : safra 2008/2009, oitavo levantamento, maio/2009. <http://www. conab.gov.br/conabweb/download/safra/8graos_08.09. pdf>. 18 Ago. 2009.

Crusciol, C. A. C.; Garcia, R. A.; Castro, G. S. A.; Rosolem, C. A. Nitrate role in basic cation leaching under no-till. Revista Brasileira de Ciência do Solo, v.35, n.6, p.1975-1984, 2011. $<$ http://dx.doi.org/10.1590/S0100-06832011000600014>.

Farooq, M.; Kobayashi, N.; Wahid, A.; Ito, O.; Basra, S. M. A. Strategies for producing more rice with less water. Advances in Agronomy, v.101, p.351-388. 2009. <http:// dx.doi.org/10.1016/S0065-2113(08)00806-7>.

Fidelis, R. R.; Rotili, E. A.; Santos, M. M. dos; Barros, H. B.; Melo, A. V. de; Dotto, M. Eficiência no uso de nitrogênio em cultivares de arroz irrigado. Revista Brasileira de Ciências Agrárias, v.6. n.4, p.622-626, 2011. <http://dx.doi. org/doi:10.5039/agraria.v6i4a1359>.

Guimarães, C. M.; Moreira, J. A. A. Compactação do solo na cultura do arroz de terras altas. Pesquisa Agropecuária Brasileira, v.36, n.4, p.703-707, 2001. <http://dx.doi. org/10.1590/S0100-204X2001000400014>.

Guimarães, C. M.; Stone, L. F.; Castro, E. da M. de. Comportamento de cultivares de arroz de terras altas no sistema plantio direto em duas profundidades de adubação. Bioscience Journal, v.22. n.1, p.53-59, 2006. <http:// www.seer.ufu.br/index.php/biosciencejournal/article/ view/6639>. 28 Dez. 2012.

Holzschuh, M. J.; Bohnen, H.; Anghinoni, I.; Meurer, E. J.; Carmona, F. C.; Costa, S. E. V. G. A. Rice growth as affected by combined ammonium and nitrate supply. Revista Brasileira de Ciência do Solo, v.33, n.5, p.1323-1331, 2009. $<$ http://dx.doi.org/10.1590/S0100-06832009000500025>.

Kluthcouski, J.; Fancelli, A. L.; Dourato-Neto, D.; Ribeiro, C. M.; Ferraro, L. A. Manejo do solo e o rendimento de soja, milho, feijão e arroz em plantio direto. Scientia Agricola, v.57, n.1, p.97-104, 2000. <http://dx.doi.org/10.1590/ S0103-90162000000100016>.

Kronzucker, H. J.; Kirk, G. J. D.; Yaeesh, S. M.; Glass, A. D. M. Effects of hypoxia on $13 \mathrm{NH}_{4}^{+}$fluxes in rice roots kinetics and compartmental analysis. Plant Physiology, v.116, n.2, p.581-587, 1998. <http://dx.doi.org/10.1104/ pp.116.2.581>. 
Li, Y. L.; Zhang, Y. L.; Shen, Q. R. Contribution of nitrification happened in rhizospheric soil growing with different rice cultivars to N nutrition. Biology and Fertility of Soils, v.43, n.4, p.417-425, 2007. <http://dx.doi.org/10.1007/s00374006-0119-0>.

Lin, S.; Li, J.; Sattelmacher, B.; Bruck, H. Response of lowland and aerobic rice to ammonium and nitrate supply during early growth stages. Journal of Plant Nutrition, v.28, n.9, p.14951510, 2005. <http://dx.doi.org/10.1080/01904160500201394>.

Malavolta, E. Elementos de nutrição mineral de plantas. São Paulo: Agronômica Ceres, 1980. 251p.

Martins, D.; Martins, C. C.; Costa, N. V. Potencial alelopático de soluções de solo cultivado com Brachiaria brizantha: efeitos sobre a germinação de gramíneas forrageiras e plantas daninhas de pastagens. Planta Daninha, v.24, n.1, p.61-70, 2006. <http://dx.doi.org/10.1590/S0100$83582006000100008>$.

Moreira, F. M. S.; Siqueira, J. O. Microbiologia e bioquímica do solo. Lavras: Universidade Federal de Lavras, 2002. 625p.

Moro, E. Formas de nitrogênio no solo e produção do arroz de terras altas em plantio direto. Botucatu: Faculdade de Ciências Agronômicas, Universidade Estadual Paulista, 2011. 120p. Tese Doutorado.

Moura Neto, F. P.; Soares, A. A.; Aidar, H. Desempenho de cultivares de arroz de terras altas sob plantio direto e convencional. Ciência e Agrotecnologia, v.26, n.5, p.904910, 2002. <http://www.cloud.editora.ufla.br/revistas/ cienagro/pdf/26-5-2002_04.pdf>. 28 Dez. 2012.

Nascente, A. S. Crusciol, C. A. C.; Stone, L. F.; Cobucci, T. Upland rice yield as affected by previous summer crop rotation (soybean or upland rice) and glyphosate management on cover crops. Planta Daninha, v.31, n.1, p.147-155, 2013. $<$ http://dx.doi.org/10.1590/S0100-83582013000100016>.

Nascente, A. S. Produtividade do arroz de terras altas em razão da época de dessecação das plantas de cobertura. Botucatu: Faculdade de Ciências Agronômicas, Universidade Estadual Paulista, 2012. 94p. Tese Doutorado.

Nascente, A. S.; Guimarães, A. S.; Cobucci, C. M.; Crusciol, C. A. C. Brachiaria ruziziensis and herbicide on the yield of upland rice. Planta Daninha, v.30, n.4, p.729-736, 2012. $<$ http://dx.doi.org/10.1590/S0100-83582012000400006 >.

Nascente, A. S.; Kluthcouski, J.; Rabelo, R. R.; Oliveira, P. de; Cobucci, T.; Crusciol, C. A. C. Produtividade do arroz de terras altas em função do manejo do solo e época de aplicação de nitrogênio. Pesquisa Agropecuária Tropical, v.41, n.1, p.6065, 2011a. <http://dx.doi.org/10.5216/pat.v41i1.6509>.
Nascente, A. S.; Kluthcouski, J.; Rabelo, R. R.; Oliveira, P. de; Cobucci, T.; Crusciol, C. A. C. Desenvolvimento e produtividade de cultivares de arroz de terras altas em função do manejo do solo. Pesquisa Agropecuária Tropical, v.41, n.2, p.186-192, 2011b. <http://dx.doi.org/10.5216/ pat.v41i2.6980>.

Nunes, T.; Adorian, G.; Terra, T.; Leal, T.; Santos, A.; Ramos, P. Aspectos produtivos de linhagens de arroz de terras altas sob déficit hídrico. Revista Brasileira de Ciências Agrárias, v.7, n.1, p. 51-57, 2012. <http://dx.doi.org/10.5039/agraria. v7ila1411>.

Pacheco, L. P.; Barbosa, J. M.; Leandro, W. M.; Machado, P. L. O. de O.; Assis, R. L. de; Madari, B.E.; Petter, F.A. Produção e ciclagem de nutrientes por plantas de cobertura nas culturas de arroz de terras altas e de soja. Revista Brasileira de Ciência do Solo, v.35, n.5, p.1787-1800, 2011. <http://dx.doi.org/10.1590/S010006832011000500033>.

Poletto, N.; Mundstock, C. M.; Grohs, D. S.; Mazurana, M. Padrão de afilhamento em arroz afetado pela presença dos íons amônio e nitrato. Bragantia, v.70, n.1, p.96-103, 2011. <http://dx.doi.org/10.1590/S000687052011000100015>.

Santos, A. B. dos; Stone, L. F.; Vieira, N. R. de A. (Ed.). A cultura do arroz no Brasil. 2. ed. rev. ampl. Santo Antônio de Goiás: Embrapa Arroz e Feijão, 2006. 1000p.

Sentelhas, P. C.; Pereira, A. R.; Marin, F. R.; Angelocci, L. R.; Alfonsi, R. R.; Caramori, P. H.; Swart, S. (Orgs.). BHBRASIL: balanços hídricos climatológicos de 500 localidades brasileiras. <http://www.leb.esalq.usp.br/ bhbrasil/Goias/>. 15 Abr. 2010.

Souza Filho, A. P. S.; Rodrigues, L. R. A.; Rodrigues, T. J. D. Potencial alelopático de forrageiras tropicais: efeitos sobre invasoras de pastagens. Planta Daninha, v.15, n.1, p.53-60, 1997. <http://dx.doi.org/10.1590/S010083581997000100007>.

Souza, L. S.; Velini, E. D.; Martins, D.; Rosolem, C. A. Efeito alelopático de capim-braquiária (Brachiaria decumbens) sobre o crescimento inicial de sete espécies de plantas cultivadas. Planta Daninha, v.24, n.4, p.657-668, 2006. $<$ http://dx.doi.org/10.1590/S0100-83582006000400006>.

Stone, L. F.; Silveira, P. M. da. Efeitos do sistema de preparo e da rotação de culturas na porosidade e densidade do solo. Revista Brasileira de Ciência do Solo, v.25, n.2, p.395-401, 2001. <http://sbcs.solos.ufv.br/solos/revistas/v25n2a15. pdf>. 20 Dez. 2012. 